\title{
The effects of mental health on recurrent falls among elderly adults, based on Korean Community Health Survey data
}

\author{
Kyung Hee Jo', Jong Park², So Yeon Ryu² \\ 'Department of Public Health, Graduate School of Chosun University, Gwangju, Korea; ${ }^{2}$ Department of Preventive Medicine, Chosun University \\ Medical School, Gwangju, Korea
}

OBJECTIVES: This study aimed to identify the effect of mental health on frequency of falls (single and recurrent falls) among elderly adults.

METHODS: Data were drawn from the 2015 Korean Community Health Survey. A chi-square test was conducted to compare differences in fall frequency according to health-related behaviors, chronic diseases, and mental health. Subsequently, multinomial logistic regression analysis was used to identify the effects of mental health on single and recurrent falls based on variables found to be significant in the chi-square test.

RESULTS: Recurrent falls were found to be more risky than single falls. Depression was significantly related to single falls (odds ratio [OR], 1.27; 95\% confidence interval [CI], 1.12 to 1.44). Depression (OR, 1.56; 95\% CI, 1.38 to 1.76), sleep disorder (5 hours or less: OR, 1.12; $95 \%$ CI, 1.02 to 1.23 ; more than 9 hours: OR, 1.24; $95 \%$ CI, 1.07 to 1.44, respectively), and subjective stress (OR, 2.30 ; $95 \% \mathrm{CI}, 1.90$ to 2.78 ) were significantly related to recurrent falls.

CONCLUSIONS: The study's findings suggest that specialized fall prevention programs are needed to address different types of falls in elderly adults. To prevent recurrent falls, systematic treatment strategies and rehabilitation training must improve physical function and mental health.

KEY WORDS: Accidental falls, Mental health, Depression, Aged, Korea Community Health Survey

\section{INTRODUCTION}

A fall refers to sustaining a physical injury from collapsing to the ground or tumbling down from a height, and can occur in people of all ages. In elderly adults, falling is the second most common cause of accidental death, following traffic accidents [1]. Ap-

\section{Correspondence: Jong Park}

Department of Preventive Medicine, Chosun University Medical School, 309 Pilmun-daero, Dong-gu, Gwangju 61452, Korea

E-mail:jpark@chosun.ac.kr

Received: Nov 7, 2019 / Accepted: Feb 2, 2020 / Published: Feb 2, 2020

This article is available from: http://e-epih.org/

(c) This is an open-access article distributed under the terms of the Creative Commons Attribution License (https://creativecommons.org/licenses/by/4.0/), which permits unrestricted use, distribution, and reproduction in any medium, provided the original work is properly cited.

(C) 2020, Korean Society of Epidemiology proximately $30 \%$ of people aged 65 or over experience a fall, and $50 \%$ of those experience recurrent falls, making the factor a considerable threat to health in elderly populations [2].

In Korea, approximately 7.38 million people were 65 or older in 2018, constituting $14.3 \%$ of the country's total population. Countries with an elderly population of $7 \%$ or more are generally classified as "aging societies"; countries like Korea, with an elderly population of $14 \%$ or more, are classified as "aged societies." Furthermore, because Korea's elderly population rate is continuing to increase, falls are a serious health issue [3].

Because bone density and muscle mass decrease with aging, elderly people's bones can fracture with even a small shock. In the event of a fall, physical injuries are more likely to occur, including fractures, bruises, hematoma, edema, and other complications [4]. Mortality due to falls has steadily increased in those over 65 , from 18.6 deaths per 100,000 population in 2015 to 20.3 in 2016 to 21.1 in 2017 [5]. The number of patients admitted to the hospital due to 
falls rose by $32 \%$ to approximately 124,000 between 2011 and 2015, with corresponding increases in socioeconomic costs [7]. Additionally, economic burdens are heightened when falls result in complications, which prolongs treatment and the related expenditures [6].

Major risk factors for falls, which interact in a complex fashion, include old age, female gender, living alone, drinking, chronic illness, previous experience of falls, low quality of life, depression, and dangerous environmental factors $[8,9]$. Recently, mental health has also been identified as a major risk factor. The risks of both falls in general and recurrent falls were particularly high in elderly adults with severe depression [10]. Depression in elderly adults decreases cognitive functioning and affects physical functioning, increasing the risk of falls $[11,12]$.

Preventing single falls is difficult because they usually occur suddenly and by accident [13]. However, recurrent falls are common in older, feeble adults with numerous health complications or mental or physical problems [13]. Once elderly individuals experience one fall, anxiety and fear of falling again drives them to limit everyday activities, which reduces motor functioning and consequently increases their risk of a recurrent fall [14]. Because the mechanisms for single and recurrent falls are different, it is crucial to differentiate fall cases according to frequency and compare them accordingly [14].

Many studies have examined factors influencing falls in elderly adults. Most studies conducted in Korea have identified risk factors using a fall risk assessment model in small study samples [1517], and studies on the relationship of mental health to falls have examined only the effect of depression $[18,19]$. Thus, the effects of mental health on falls have not been sufficiently investigated. The present study aimed to differentiate and examine the characteristics of individuals who experienced single and recurrent (two or more) falls using community-based data, and thereby to explore the effects of mental health on single and recurrent falls.

\section{MATERIALS AND METHODS}

\section{Study materials and subjects}

This study used raw data from the 2015 Korean Community Health Survey (KCHS) managed by the Korean Centers for Disease Control and Prevention. The KCHS survey population included adults aged 19 or older living in each of the country's regions. After selecting sampling units using a probability proportional to size method, systematic sampling was used to select households from within each of the sampling units. Data from approximately 900 individuals were collected at 254 public health centers nationwide, and trained survey conductors visited subjects in the sampled households between August 31, 2015 and November 8, 2015. The survey included a total of 198 items across 19 domains and was administered via one-on-one interview using a laptop on which the survey program was installed [20].

Of the 228,558 total survey respondents in the $2015 \mathrm{KCHS}$, 63,929 were over age 65 . The present study's analysis included 63,899 respondents, excluding 30 due to incomplete responses to the items regarding experience of falls within the past year and number of accidental falls.

\section{Study variables}

To identify factors influencing falls in elderly adults over 65, this study examined socio-demographic factors, health behaviors, physical health-related variables, and mental health-related variables.

\section{Fall-related variables}

Experience of falls was categorized as "none," "once," or "twice or more," based on the number of falls experienced by respondents who responded yes to the question on whether they fell within the past year. Fear of falls was categorized as "not at all afraid," "a little afraid," or "very afraid," based on the question, "In general, are you afraid of falling?" Treatment due to falls during the past year was categorized as "yes" or "no" based on the question, "Have you fallen in the past 1 year?" Being bedridden was also categorized as "yes" or "no" based on the question, "In the past 1 month, have you been bedridden for almost all day due to an illness or injury?"

\section{Socio-demographic factors}

Socio-demographic factors included gender, age, education level, marital status, living arrangement, monthly income, residence type, locality, and national basic livelihood recipient status. Gender was categorized as men or women. Education level was grouped into five categories according to the respondents' final year of education and whether they graduated: no formal education, elementary school, middle school, high school, and college or higher. Marital status was categorized as either having a spouse if the respondent had a spouse, or having no spouse if the respondent was divorced, separated, widowed, or not married. Categories for living arrangement included living alone, living with spouse, and living with family or others. Monthly income was categorized as less than 1 million Korean won (KRW), 1-2 million KRW, 2-3 million KRW, or 3 million KRW or more. Residence type was classified as "house" or "apartment," and locality was classified as "urban" if the respondent lived in a dong (neighborhood) in the administrative division or as "rural" if the respondent lived in an eup (town) or myeon (township). National basic livelihood recipient status was classified as "yes" or "no."

\section{Health behaviors}

Smoking was classified as "yes" for respondents who answered that they smoked every day or occasionally, and as "no" for respondents who answered that they did not smoke, or smoked previously but not currently. Drinking was categorized as "no (less than once a month)," "low to moderate (1-4 times per month)," and "high risk (twice or more per week)"; specifically "high-risk" drinking was defined as drinking over seven glasses of soju for men and over five glasses for women twice per week or more. For physical activity, moderate intensity was coded "yes" if the respondent exercised for 20 minutes or more at least three days a week, and if 
the high intensity was coded "yes" if the respondent exercised for 30 minutes or more at least five days a week. Walking was coded "yes" for respondents who walked for 30 minutes or more at least five days a week. Subjective health was classified as "good," "average," or "poor" based on the question, "In general, how do you perceive your health?” Body mass index (BMI) was computed using respondents' height and weight, and classified as "underweight $\left(<18.5 \mathrm{~kg} / \mathrm{m}^{2}\right)$," "healthy weight $\left(18.5-24.9 \mathrm{~kg} / \mathrm{m}^{2}\right)$," "obese $(25.0-$ $\left.29.9 \mathrm{~kg} / \mathrm{m}^{2}\right)$," and "severely obese $\left(\geq 30.0 \mathrm{~kg} / \mathrm{m}^{2}\right)$."

\section{Physical health-related variables}

Hypertension, diabetes, dyslipidemia, and arthritis were coded "yes" or "no" according to whether the respondent was currently receiving treatment for the corresponding condition. Number of chronic illnesses was coded as $0,1,2$, or 3 based on the total number of conditions (hypertension, diabetes, and arthritis) the respondent was receiving treatment for.

\section{Mental health-related variables}

Subjective stress was categorized as "very much," "much," "a little," and "rarely" based on the question, "In general, how stressed do you feel in everyday life?" Depression was coded as "yes" or "no" based on the question, "In the past 1 year, have you felt sadness or despair to the extent that you could not complete everyday activities for 2 consecutive weeks or more?" Daily sleep duration was categorized as " 5 hours or less," "6-8 hours," and "more than 9 hours," with 5 hours or less or more than 9 hours being defined as sleep disorder [21].

\section{Statistical analysis}

All statistical analyses were performed using SPSS version 25.0 (IBM Corp., Armonk, NY, USA). Independent variables with the potential to influence falls were selected based on a review of the literature on falls. The statistical analysis accounted for the complex sample design taken into account, with individual weights computed and applied to the population. To examine the differences between the single and recurrent fall groups according to each of the variables, a chi-square test was performed. To examine between-group differences with respect to the relevant variables, complex-sample multinomial logistic regression analysis was conducted with fall frequency as the dependent variable and individuals over 65 as the study population to estimate odds ratios (ORs). Statistical significance was determined by a p-value of less than 0.05 .

\section{Ethics statement}

The raw data were requested from the KCHS homepage (http: //chs.cdc.go.kr/), and were obtained with all private information remaining anonymous.

\section{RESULTS}

\section{Subjects' fall-related characteristics}

Among the study's subjects, $19.6 \%$ had experienced at least one fall within the past year and $80.4 \%$ had not. Over the past year, $11.6 \%$ had fallen once and $8.0 \%$ had fallen twice or more; $48.1 \%$ received treatment for a fall and $51.9 \%$ did not (Table 1). A total of $38.8 \%$ indicated they were "not afraid at all" of falling, $37.7 \%$ were "a little afraid," and 23.5\% were "very afraid." Fall experiences, overall falls, and recurrent falls were highest among those with the greatest fear of falling. Of all subjects, $8.1 \%$ had been bedridden and $91.9 \%$ had not. Those who had been bedridden had higher rates of fall experiences and recurrent falls (Table 2).

Table 1. Fall-related characteristics of adults aged 65 and older $(n=$ 63,899)

\begin{tabular}{lrr}
\hline Variables & $\mathrm{n}$ & $\%$ (\% standard error) \\
\hline Fall experience & & \\
$\quad$ Yes & 12,659 & $19.6(0.2)$ \\
$\quad$ No & 51,240 & $80.4(0.2)$ \\
No. of falls in the past year & & \\
0 & 51,240 & $80.4(0.2)$ \\
1 & 7,190 & $11.6(0.2)$ \\
$\geq 2$ & 5,469 & $8.0(0.1)$ \\
Treatment for a fall within the past year & \\
Yes & 5,972 & $48.1(0.6)$ \\
No & 6,687 & $51.9(0.6)$ \\
\hline
\end{tabular}

Table 2. Fall-related characteristics according to fall status in adults aged 65 and older

\begin{tabular}{|c|c|c|c|c|c|}
\hline \multirow{2}{*}{ Variables } & \multirow{2}{*}{ Total (\%) } & \multicolumn{3}{|c|}{ Fall status } & \multirow{2}{*}{$p$-value } \\
\hline & & No & Single & Recurrent & \\
\hline \multicolumn{6}{|l|}{ Fear of falling } \\
\hline Not at all afraid & 38.8 & $90.4(0.3)$ & $6.8(0.2)$ & $2.8(0.1)$ & $<0.001$ \\
\hline A little afraid & 37.7 & $81.1(0.4)$ & $11.9(0.3)$ & $7.0(0.2)$ & \\
\hline Very afraid & 23.5 & $62.8(0.5)$ & $19.0(0.4)$ & $18.1(0.4)$ & \\
\hline \multicolumn{6}{|c|}{ Bedridden in past month } \\
\hline Yes & 8.1 & $61.8(0.9)$ & $17.2(0.7)$ & $21.0(0.8)$ & $<0.001$ \\
\hline No & 91.9 & $82.1(0.2)$ & $11.1(0.2)$ & $6.8(0.1)$ & \\
\hline
\end{tabular}

Values are presented as \% (\% standard error).

${ }^{1}$ Chi-square test. 
Table 3. Differences in general characteristic and health behaviors by fall status in adults aged 65 and older

\begin{tabular}{|c|c|c|c|c|c|}
\hline \multirow{2}{*}{ Variables } & \multirow{2}{*}{ Total (\%) } & \multicolumn{3}{|c|}{ Fall status } & \multirow{2}{*}{$\mathrm{p}$-value } \\
\hline & & No & Single & Recurrent & \\
\hline General information (n) & 63,899 & 51,240 & 7,190 & 5,469 & \\
\hline Gender & & & & & $<0.001$ \\
\hline Men & 43.2 & $76.3(0.3)$ & $14.0(0.2)$ & $9.7(0.2)$ & \\
\hline Women & 56.8 & $85.9(0.2)$ & $8.4(0.2)$ & $5.7(0.2)$ & \\
\hline Age, mean $\pm S E(y r)$ & $73.91 \pm 0.06$ & $73.08 \pm 0.04$ & $73.85 \pm 0.10$ & $74.80 \pm 0.12$ & $<0.001$ \\
\hline Education level & & & & & $<0.001$ \\
\hline No formal education & 26.0 & $87.2(0.7)$ & $9.1(0.6)$ & $3.8(0.4)$ & \\
\hline Elementary school & 31.1 & $84.8(0.5)$ & $9.3(0.4)$ & $5.9(0.3)$ & \\
\hline Middle school & 15.4 & $83.2(0.6)$ & $11.2(0.5)$ & $5.6(0.3)$ & \\
\hline High school & 19.4 & $84.8(0.5)$ & $9.3(0.4)$ & $5.9(0.3)$ & \\
\hline College or higher & 8.1 & $87.2(0.7)$ & $9.1(0.6)$ & $3.8(0.4)$ & \\
\hline Marital status & & & & & $<0.001$ \\
\hline No spouse & 35.8 & $75.4(0.4)$ & $14.0(0.3)$ & $10.6(0.3)$ & \\
\hline Spouse & 64.2 & $83.2(0.3)$ & $10.3(0.2)$ & $6.5(0.2)$ & \\
\hline Living arrangement & & & & & $<0.001$ \\
\hline Alone & 19.1 & $75.3(0.5)$ & $13.7(0.4)$ & $11.0(0.3)$ & \\
\hline With spouse & 43.8 & $83.4(0.3)$ & $10.1(0.2)$ & $6.5(0.2)$ & \\
\hline With family or others & 37.1 & $79.5(0.4)$ & $12.3(0.3)$ & $8.2(0.3)$ & \\
\hline Monthly income ( $10^{4}$ Korean won) & & & & & $<0.001$ \\
\hline$<100$ & 43.2 & $77.3(0.3)$ & $12.7(0.3)$ & $10.0(0.2)$ & \\
\hline $100-200$ & 22.4 & $82.5(0.4)$ & $10.9(0.4)$ & $6.5(0.3)$ & \\
\hline $200-300$ & 14.0 & $83.3(0.6)$ & $10.7(0.5)$ & $6.0(0.4)$ & \\
\hline$\geq 300$ & 20.4 & $82.7(0.5)$ & $10.7(0.4)$ & $6.5(0.3)$ & \\
\hline Residence type & & & & & $<0.001$ \\
\hline House & 64.7 & $81.3(0.4)$ & $11.7(0.3)$ & $7.0(0.3)$ & \\
\hline Apartment & 35.3 & $79.9(0.2)$ & $11.6(0.2)$ & $8.5(0.2)$ & \\
\hline Locality & & & & & $<0.001$ \\
\hline Urban & 69.9 & $80.6(0.3)$ & $11.8(0.2)$ & $7.6(0.2)$ & \\
\hline Rural & 30.1 & $80.1(0.3)$ & $11.0(0.2)$ & $8.9(0.2)$ & \\
\hline National basic livelihood recipient status & & & & & $<0.001$ \\
\hline Yes & 6.3 & $70.9(1.0)$ & $15.1(0.8)$ & $14.0(0.7)$ & \\
\hline No & 98.7 & $81.1(0.2)$ & $11.4(0.2)$ & $7.6(0.1)$ & \\
\hline Smoking & & & & & $<0.001$ \\
\hline Yes & 9.3 & $84.6(0.6)$ & $9.4(0.5)$ & $5.9(0.4)$ & \\
\hline No & 90.7 & $80.0(0.2)$ & $11.8(0.2)$ & $8.2(0.2)$ & \\
\hline Drinking & & & & & $<0.001$ \\
\hline None & 65.9 & $78.8(0.3)$ & $12.4(0.2)$ & $8.9(0.2)$ & \\
\hline Low to moderate & 23.2 & $83.3(0.4)$ & $10.2(0.4)$ & $6.5(0.5)$ & \\
\hline High-risk & 10.9 & $85.0(0.6)$ & $9.6(0.5)$ & $5.4(0.4)$ & \\
\hline \multicolumn{6}{|l|}{ High intensity exercise } \\
\hline Yes & 9.8 & $83.6(0.7)$ & $9.9(0.6)$ & $6.5(0.4)$ & $<0.001$ \\
\hline No & 90.2 & $80.1(0.2)$ & $11.8(0.2)$ & $8.1(0.2)$ & \\
\hline Moderate intensity exercise & & & & & $<0.001$ \\
\hline Yes & 19.0 & $83.5(0.4)$ & $10.1(0.4)$ & $6.4(0.3)$ & \\
\hline No & 81.0 & $79.7(0.2)$ & $12.0(0.2)$ & $8.3(0.2)$ & \\
\hline Walking & & & & & $<0.001$ \\
\hline Yes & 51.6 & $83.0(0.3)$ & $10.7(0.3)$ & $6.3(0.2)$ & \\
\hline No & 48.4 & $77.7(0.3)$ & $12.6(0.2)$ & $9.7(0.2)$ & \\
\hline
\end{tabular}


Table 3. Continued

\begin{tabular}{|c|c|c|c|c|c|}
\hline \multirow{2}{*}{ Variables } & \multirow{2}{*}{ Total (\%) } & \multicolumn{3}{|c|}{ Fall status } & \multirow{2}{*}{$p$-value ${ }^{1}$} \\
\hline & & No & Single & Recurrent & \\
\hline Subjective health status & & & & & $<0.001$ \\
\hline Good & 21.6 & $88.7(0.4)$ & $8.1(0.3)$ & $3.3(0.2)$ & \\
\hline Average & 36.5 & $83.5(0.3)$ & $11.2(0.3)$ & $5.3(0.2)$ & \\
\hline Poor & 41.9 & $73.5(0.4)$ & $13.8(0.3)$ & $12.7(0.3)$ & \\
\hline Body mass index $\left(\mathrm{kg} / \mathrm{m}^{2}\right)$ & & & & & $<0.001$ \\
\hline Underweight $(<18.5)$ & 12.3 & $77.0(0.6)$ & $12.5(0.4)$ & $10.6(0.4)$ & \\
\hline Healthy weight (18.5-24.9) & 64.6 & $81.4(0.3)$ & $11.4(0.2)$ & $7.2(0.2)$ & \\
\hline Obese (25.0-29.9) & 21.3 & $80.3(0.5)$ & $11.3(0.4)$ & $8.5(0.5)$ & \\
\hline Severely obese ( $\geq 30.0)$ & 1.8 & $74.2(2.1)$ & $15.2(1.8)$ & $10.6(1.5)$ & \\
\hline
\end{tabular}

Values are presented as \% (\% standard error).

${ }^{1}$ Chi-square test.

Table 4. Differences in mental health and chronic illness characteristics by fall status in adults aged 65 and older

\begin{tabular}{|c|c|c|c|c|c|}
\hline \multirow{2}{*}{ Variables } & \multirow{2}{*}{ Total (\%) } & \multicolumn{3}{|c|}{ Fall status } & \multirow{2}{*}{$\mathrm{p}$-value } \\
\hline & & No & Single & Recurrent & \\
\hline Sleep duration (hr) & & & & & $<0.001$ \\
\hline$\leq 5$ & 25.5 & $77.5(0.4)$ & $12.4(0.4)$ & $10.1(0.3)$ & \\
\hline $6-8$ & 68.7 & $81.8(0.3)$ & $11.2(0.2)$ & $7.0(0.2)$ & \\
\hline$\geq 9$ & 5.8 & $76.7(0.9)$ & $13.2(0.7)$ & $10.1(0.6)$ & \\
\hline Subjective stress level & & & & & $<0.001$ \\
\hline Rarely & 35.1 & $83.3(0.3)$ & $10.9(0.3)$ & $5.7(0.2)$ & \\
\hline A little & 44.7 & $81.6(0.3)$ & $11.5(0.3)$ & $6.9(0.2)$ & \\
\hline Much & 17.3 & $73.5(0.6)$ & $13.1(0.5)$ & $13.4(0.5)$ & \\
\hline Very much & 2.9 & $67.7(1.4)$ & $13.1(1.0)$ & $19.3(1.2)$ & \\
\hline Depression & & & & & $<0.001$ \\
\hline Yes & 8.3 & $67.7(0.9)$ & $15.1(0.7)$ & $17.2(0.8)$ & \\
\hline No & 91.7 & $81.3(0.2)$ & $11.3(0.2)$ & $7.1(0.1)$ & \\
\hline Hypertension & & & & & $<0.001$ \\
\hline Yes & 51.0 & $79.3(0.3)$ & $12.0(0.2)$ & $8.7(0.2)$ & \\
\hline No & 49.0 & $81.5(0.3)$ & $11.2(0.3)$ & $7.2(0.2)$ & \\
\hline Diabetes & & & & & $<0.001$ \\
\hline Yes & 20.3 & $77.2(0.5)$ & $13.3(0.4)$ & $9.6(0.4)$ & \\
\hline No & 79.7 & $81.3(0.2)$ & $11.2(0.2)$ & $7.6(0.2)$ & \\
\hline Hyperlipidemia & & & & & $<0.001$ \\
\hline Yes & 18.4 & $77.7(0.6)$ & $13.0(0.4)$ & $9.2(0.4)$ & \\
\hline No & 81.6 & $81.1(0.2)$ & $11.3(0.2)$ & $7.7(0.2)$ & \\
\hline Arthritis & & & & & $<0.001$ \\
\hline Yes & 18.7 & $71.2(0.5)$ & $14.7(0.4)$ & $14.1(0.4)$ & \\
\hline No & 81.3 & $82.6(0.2)$ & $10.9(0.2)$ & $6.6(0.1)$ & \\
\hline No. of chronic illnesses & & & & & $<0.001$ \\
\hline 0 & 35.7 & $83.8(0.3)$ & $10.3(0.3)$ & $5.9(0.2)$ & \\
\hline 1 & 41.5 & $80.6(0.3)$ & $11.5(0.3)$ & $7.9(0.2)$ & \\
\hline 2 & 19.8 & $76.2(0.5)$ & $13.4(0.4)$ & $10.4(0.4)$ & \\
\hline 3 & 2.9 & $65.1(1.6)$ & $16.8(1.4)$ & $18.1(1.2)$ & \\
\hline
\end{tabular}

Values are presented as \% (\% standard error).

${ }^{1}$ Chi-square test. 
Table 5. Effects of mental health on risk of falls by fall status

\begin{tabular}{lll}
\hline \multirow{2}{*}{ Variables } & \multicolumn{2}{c}{ Fall status } \\
\cline { 2 - 3 } & \multicolumn{1}{c}{ Single } & \multicolumn{1}{c}{ Recurrent } \\
\hline $\begin{array}{l}\text { Sleep duration }(\mathrm{hr}) \\
\leq 5\end{array}$ & $1.01(0.93,1.10)$ & $1.12(1.02,1.23)^{*}$ \\
$6-8$ & 1.00 (reference) & 1.00 (reference) $^{*}$ \\
$\geq 9$ & $1.15(0.99,1.32)$ & $1.24(1.07,1.44)^{*}$ \\
Subjective stress level & & \\
$\quad$ Rarely & 1.00 (reference) & 1.00 (reference) $^{*}$ \\
A little & $1.03(0.95,1.12)$ & $1.21(1.09,1.34)^{* * *}$ \\
$\quad$ Much & $1.09(0.98,1.22)$ & $1.82(1.62,2.04)^{* * *}$ \\
$\quad$ Very much & $1.06(0.87,1.29)$ & $2.30(1.90,2.78)^{* * *}$ \\
Depression & & \\
$\quad$ No & 1.00 (reference) $^{*}$ & 1.00 (reference) $^{*}$ \\
Yes & $1.27(1.12,1.44)^{* * *}$ & $1.56(1.38,1.76)^{* * *}$ \\
\hline
\end{tabular}

Values are presented as odds ratio ( $95 \%$ confidence interval). Values adjusted for gender, age, education level, marital status, living arrangement, monthly income, residence type, locality, national basic livelihood recipient status, smoking, drinking, high intensity exercise, moderate intensity exercise, walking, body mass index, sleep duration, subjective stress level, depression, hypertension, diabetes, hyperlipidemia, arthritis, number of chronic illnesses, and subjective health status. ${ }^{*} p<0.05,{ }^{* * *} p<0.001$.

\section{General characteristics and health behaviors according to fall frequency}

Fall experiences and recurrent falls were higher in men than women. Mean age was 73.1 years in the group with no experience of falls, 73.9 in the single fall group, and 74.8 in the recurrent fall group, showing an increase in fall frequency with increasing age. Falls were more frequent in individuals without a spouse than in those with a spouse, and among those living alone compared to those living with a spouse. The rate of single falls was higher in the urban area, and the rate of recurrent falls was higher in the rural area. National basic livelihood recipients demonstrated higher rates of fall experience and recurrent falls. Fall experience and recurrent falls were higher in those who did not smoke or drink than in those who did smoke or drink. Respondents who engaged in walking or high/moderate intensity physical activity had lower rates of fall experience and recurrent falls. Respondents whose subjective health was poor had higher rates of fall experience and recurrent falls. Fall experience was higher in severely obese individuals, and recurrent falls were most common in both underweight and severely obese individuals. Between-group differences were statistically significant for all the measured variables (Table 3).

\section{Mental health and chronic illness according to fall frequency}

Higher rates of single and recurrent falls were found in respondents who slept 5 hours or less or more than 9 hours a day; had higher subjective stress; had experienced depression; were currently receiving treatment for hypertension, diabetes, dyslipidemia, or arthritis; and had a higher number of chronic illnesses. Ad- ditionally, rates of single and recurrent falls increased with decrease in respondents' subjective health status. All variables related to mental health and chronic illness were statistically significantly different between groups (Table 4).

\section{Effects of mental health on frequency of falls}

Multinomial logistic regression analysis showed that in the single fall group, fall risk was higher in elderly adults with experience of depression (OR, 1.27; 95\% confidence interval, 1.12 to 1.44). In the recurrent fall group, fall risk was higher in elderly adults with experience of depression (OR, 1.56; 95\% CI, 1.38 to 1.76) and in those who slept for 5 hours or less or more than 9 hours (OR, 1.12 ; $95 \% \mathrm{CI}, 1.02$ to 1.23 ; OR, 1.24 ; $95 \% \mathrm{CI}, 1.07$ to 1.44 , respectively). Additionally, risk of recurrent falls was greater in those with high subjective stress (OR, 2.30; 95\% CI, 1.90 to 2.78) than in those with only a little subjective stress (OR, 1.21; 95\% CI, 1.09 to 1.34) (Table 5).

\section{DISCUSSION}

Health status influences the risk of falls in elderly adults, and this includes not only physical health but also mental health. In elderly adults with more vulnerable health status, single falls are more likely to recur and have a serious effect on health, potentially leading to death [13].

In Korea, approximately $19.6 \%$ of adults 65 or older experienced at least one fall within the past year. Of those, $59.2 \%$ experienced a single fall and $40.8 \%$ experienced recurrent falls (two or more). A study of 329 community-dwelling elderly adults in a rural area found that $73.3 \%$ experienced single falls and $21.7 \%$ experienced recurrent falls, respectively [22]. Another found that among 104 community-dwelling elderly adults who were registered at regional public health centers and welfare service centers, $55.7 \%$ experienced a single fall and $44.2 \%$ experienced recurrent falls [15]. However, these previous studies were conducted with non-representative samples, which could mean that inconsistencies in the subjects' characteristics affected the studies' findings. Thus, a precise understanding of falls in the Korean elderly population has thus far been difficult. To fill this gap, the present study used data from the $2015 \mathrm{KCHS}$ to investigate the effects of mental health on falls in elderly adults, differentiating between single and recurrent fall cases.

The study found that risk of single falls increased with depression, and that risk of recurrent falls increased with depression, sleep disorder (sleeping 5 hours or less or more than 9 hours per day), and greater subjective stress. Thus, mental health was demonstrated to have a greater effect on recurrent falls among elderly adults. Additionally, people who experience recurrent falls tend to reduce their physical activity in everyday life due to fear of falling, which affects them emotionally and increases the likelihood of falling again [15].

Among people who fell once, fall risk significantly increased by 1.27 times in those who experienced depression. This is consist- 
ent with a study conducted outside Korea, which demonstrated that greater depression was associated with higher risk of falls in elderly adults [23]. A study conducted in Korea also found a higher risk of falls in respondents with depression [19]. Depression deteriorates mental functions in elderly adults, lowering their cognitive functioning and also affecting their physical functioning. These mechanisms are speculated to increase the risk of falls $[11,12]$. In those who experienced recurrent falls, depression increased the risk of falls by 1.56 times, a greater risk than in the single fall group. Fall recurrence has been reported to correlate highly with depression [21], with a $45 \%$ higher rate of fall recurrence in patients with depression [24]. Additionally, research has reported that a major factor in recurrent falls is that after an initial fall, subjects' physical functioning and social activity decrease due to physical injury, consequently increasing depression [18].

Mental health is closely associated with sleep duration and quality. Conventionally, a sleep duration of 5 hours or less or more than 9 hours is defined as sleep disorder [21]. In this study, individuals with sleep disorder in the recurrent fall group tended to have increased fall risk. This risk was particularly increased for those who overslept (more than 9 hours). Some studies report that sleep quality may be much lower in oversleeping (more than 9 hours) than sleep deprivation (5 hours or less) [25]. Poorer sleep quality deteriorates physical health and affects mental and cognitive functioning, which can influence falls [26], and the risk of another fall increases in elderly individuals who have already fallen [27]. However, various aspects must be considered when assessing sleep, including amount of sleep, number of arousals, and sleep latency [28], so it is difficult to assess sleep based on duration alone. Research examining the effects of sleep on recurrent falls is also extremely scarce. Thus, future research on this topic is needed.

Subjective stress was also found to influence falls in the recurrent fall group, indicating that higher subjective stress increases the risk of fall recurrence. Whereas a single fall tends to occur due to a sudden accident, recurrent falls occur because fear of falling increases with recurrent fall experiences, adding to psychological stress [13]. These negative effects eventually impact individuals' physical activity and functional recovery capacity [29]. Accordingly, mental health promotion programs to enhance self-efficacy and reduce stress should be provided for elderly individuals who experience recurrent falls, in parallel with training to regain physical functioning.

This cross-sectional study confirmed the effects of mental health on falls among elderly adults. Additionally, the results demonstrated that mental health had greater effects on recurrent falls. A variety of complex factors are speculated to affect elderly adults' emotional states, for example increasing their sleep and subjecting them to stress and depression, but it was difficult to explain the temporal relationships among mental health variables. Additionally, the study's results cannot describe the directionality of the relationship between recurrent falls and mental health. However, this study is significant in that it was based on a representative, communitybased database and demonstrated the differing effects of mental health on risk of single and recurrent falls.

In conclusion, the risk of recurrent falls may increase in Korean elderly adults as mental health status grows more vulnerable through stress, depression, and sleep disorder. Whereas single falls tend to occur due to a sudden accident, recurrent falls primarily occur in high-risk groups. Therefore, it is possible to prevent recurrent falls. Accordingly, fall prevention programs should be developed to manage specific risk factors according to individuals' fall frequency. For people experiencing recurrent falls in particular, systematic treatment strategies and rehabilitation training are necessary to improve both mental health and physical functioning.

\section{SUPPLEMENTARY MATERIALS}

Korean version is available at http://www.e-epih.org/.

\section{CONFLICT OF INTEREST}

The authors have no conflicts of interest to declare for this study.

\section{FUNDING}

None.

\section{ACKNOWLEDGEMENTS}

None.

\section{AUTHOR CONTRIBUTIONS}

Conceptualization: KHJ, JP. Data curation: KHJ. Formal analysis: KHJ. Funding acquisition: None. Methodology: KHJ, JP, SYR. Project administration: JP, SYR. Visualization: KHJ. Writing - original draf: KHJ. Writing - review \& editing: KHJ, JP, SYR.

\section{ORCID}

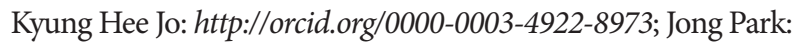
http://orcid.org/0000-0003-3353-3543; So Yeon Ryu: http://orcid.org/ 0000-0001-5006-1192

\section{REFERENCES}

1. World Health Organization. The injury chart book: a graphical overview of the global burden of injuries; 2002 [cited 2019 Jan 15]. Available from: https://www.who.int/publications-detail/theinjury-chart-book-a-graphical-overview-of-the-global-burdenof-injuries.

2. Ruchinskas R. Clinical prediction of falls in the elderly. Am J Phys Med Rehabil 2003;82:273-278.

3. Statistics Korea. 2018 Elderly statistics; 2018 [cited 2019 Jan 4]. Available from: http://kostat.go.kr/portal/korea/kor_nw/1/1/index.board bmode $=$ read\&aSeq $=370779$ (Korean). 
4. Ryeom TH, Kim SY, So YK, Park SY, Lee JH, Cho HS, et al. The risk factors of falls in the elderly. J Korean Acad Fam Med 2001; 22:221-229 (Korean).

5. Korean Statistical Information Service. Annual report on the cause of death statistics; 2017 [cited 2019 Jan 10]. Available from: http://kosis.kr/statHtml/statHtml.do?orgId = 101\&tblId = DT_1B 34E01\&vw_cd = MT_ZTITLE\&list_id = D11\&seqNo = \&lang mode $=$ ko\&language $=$ kor\&obj_var_id $=$ \&itm_id $=\&$ conn path $=$ MT_ZTITLE (Korean).

6. Tinetti ME, Speechley M, Ginter SF. Risk factors for falls among elderly persons living in the community. N Engl J Med 1988;319: 1701-1707.

7. Korea Centers for Disease Control and Prevention (KCDC). National injury fact book 2015-2016. Cheongju: KCDC; 2018, p. 7980 (Korean).

8. Rubenstein LZ, Josephson KR. Falls and their prevention in elderly people: what does the evidence show? Med Clin North Am 2006;90:807-824.

9. Letts L, Moreland J, Richardson J, Coman L, Edwards M, Ginis $\mathrm{KM}$, et al. The physical environment as a fall risk factor in older adults: systematic review and meta-analysis of cross-sectional and cohort studies. Aust Occup Ther J 2010;57:51-64.

10. Yeom JH, Na HJ. Risk factors of falls among Korean elderly. J Korean Gerontol Soc 2012;32:577-592 (Korean).

11. Turcu A, Toubin S, Mourey F, D’Athis P, Manckoundia P, Pfitzenmeyer P. Falls and depression in older people. Gerontology 2004; 50:303-308.

12. Rock PL, Roiser JP, Riedel WJ, Blackwell AD. Cognitive impairment in depression: a systematic review and meta-analysis. Psychol Med 2014;44:2029-2040.

13. Fletcher PC, Hirdes JP. Risk factors for falling among community-based seniors using home care services. J Gerontol A Biol Sci Med Sci 2002;57:M504-M510.

14. Hong SH, Cho EH, Choi MY. Risk factors for falls among community-dwelling older adults-using KLoSA data. J Korean Gerontol Nurs 2010;12:211-224 (Korean).

15. Yoo IY. Analysis of multi-variate recurrent fall risk factors in elderly people using residential assessment instrument-home care: comparisons between single and recurrent fallers. J Korean Acad Nurs 2011;41:119-128 (Korean).

16. Kang KS, Yang J. A study on the fear of falling, activity of daily living and quality of life for the elderly. J Korea Acad Ind Coop Soc 2017;18:193-199 (Korean).

17. Lee HJ, Lee TY, Tae KS. A study on the prediction of fall factors for the elderly living in the city. J Rehabil Welf Eng Assist Technol 2018;12:46-52 (Korean).

18. Nam IS, Yoon HS. An analysis of the interrelationship between depression and falls in Korean older people. J Korea Gerontol Soc 2014;34:523-537 (Korean).

19. Kim SG, Kim S, Kim KH, Jeong SM, Ko A, Han SV, et al. The association between depression and falls in Korean adults aged 45 years or older. Korean J Fam Pract 2018;8:696-702 (Korean).

20. Korea Centers for Disease Control and Prevention. Community Health Survey 2015 [cited 2019 May 10]. Available from: https:// chs.cdc.go.kr/chs/mnl/mnlBoardMain.do (Korean).

21. Kim MS, Kim JI. Relationship among the health state, daily living activities (ADL, IADL), sleep state, and depression among old people at elderly care facilities. J Korea Acad Ind Coop Soc 2015; 16:2609-2619 (Korean).

22. Jeon MY, Yang SH. Risk factors for recurrent falls among community-dwelling elderly in rural areas. J Korea Acad Ind Coop Soc 2013;14:6353-6363 (Korean).

23. Kvelde T, McVeigh C, Toson B, Greenaway M, Lord SR, Delbaere $\mathrm{K}$, et al. Depressive symptomatology as a risk factor for falls in older people: systematic review and meta-analysis. J Am Geriatr Soc 2013;61:694-706.

24. Marcum ZA, Perera S, Thorpe JM, Switzer GE, Castle NG, Strotmeyer ES, et al. Antidepressant use and recurrent falls in community-dwelling older adults: findings from the Health ABC Study. Ann Pharmacother 2016;50:525-533.

25. Kwon E, Kim B, Won C, Choi H, Kim S, Kim K, et al. The effect of sleep duration and regularity on cardio-cerebrovascular disease: community-based prospective study. Korean J Fam Pract 2018;8:729-734 (Korean).

26. Ancoli-Israel S. Sleep and its disorders in aging populations. Sleep Med 2009;10:S7-S11.

27. Shin KR, Gong SJ, Kang Y, Oak JW, Lim EJ. The relationship of late-life function and disability (LLFDI) with quality of sleep in older men with prostatic hypertrophic symptoms. J Korean Acad Adult Nurs 2009;21:43-52 (Korean).

28. Pilcher JJ, Ginter DR, Sadowsky B. Sleep quality versus sleep quantity: relationships between sleep and measures of health, well-being and sleepiness in college students. J Psychosom Res 1997;42: 583-596.

29. Park CS, Kim WG, An SH. The study on predicting of fall incidence using the falls-related efficacy scale in people with chronic stroke. J Spec Educ Rehabil Sci 2013;52:241-258 (Korean). 